\title{
Special Modes of AC Drives Operation in the Mining Industry
}

\author{
Lubov Payuk ${ }^{1, *}$, Nataliya Voronina $^{1}$, Olga Galtseva ${ }^{1}$, Dini Zhang $^{1}$, and Alexandr Rogachev ${ }^{2}$ \\ ${ }^{1}$ Tomsk Polytechnic University, 634050, Tomsk, Russia \\ ${ }^{2}$ Francisk Skorina Gomel State University, 246019, Gomel, Belarus
}

\begin{abstract}
This paper presents research of special modes of AC drives operation. The possibility of obtaining of vibrational and vibrationalrotational modes of the AC drives on the basis of multipurpose polyharmonic mode of actuating motor operation is shown. Multipurpose electric motor with improved power characteristics (double-fed machine) has been proposed as the actuating motor of the electroactivator of the coal grizzley. The formation algorithm of polyharmonic operation mode of the double-fed machine is developed. This algorithm allows studying different types of special modes of actuating motor. Research results of dynamic parameters of a universal electric motor of the electroactivator of the coal grizzley are presented. The practical significance of the study of using of double-fed machine in the primary coal processing is shown.
\end{abstract}

\section{Introduction}

In modern mining industry a wide variety of high-precision and technological equipment is used. It is based on modern trends using generally accepted drives [1-3]. It is therefore not surprising that in practice the different from "classical" modes of AC drives (ACD) operation are applied. This is mainly vibrational, vibrational-rotational, polyharmonic and other electric drives operating in the special modes [4-6]. They are used in primary coal fragmenting, coal vibro-sorting, vibrational screen separators at the ore beneficiation, lifting mechanisms, etc. Requirements on the mechanical oscillations parameters in the mining industry are relatively high, because its cost depends on the quality of finished materials. The ranges of required frequencies, amplitudes and speed-ups are $3 \div 150[\mathrm{~Hz}], 0.5 \div 90$ $[\mathrm{mm}], 2 \div 104[\mathrm{~m} / \mathrm{s}]$ for the linear parameters and $15 \div 100[\mathrm{~Hz}] 10 \div 2.2[\mathrm{rad}], 5 \div 500[\mathrm{rad} / \mathrm{s}]$ for the angular parameters, respectively [7].

It's worth to mention that the most interesting mode is polyharmonic, because algorithm of its formation (it will be proposed below) takes into account the possibility of obtaining another types of the ACD "special" modes. In the mining industry considered ACD operation mode is used in vibrotransportation and coal vibro-sorting for the primary processing (example, in the grizzlies systems).

According to the Russian state standart GOST 23788-79 the grizzlies are divided on light, medium and heavy. Grizzley is a set of vibrating sieves with the decreasing meshs,

'Corresponding author: lubapa81@mail.ru 
which are separated according to the meshs coarseness and the finished product (iron and copper ores, coal, etc.), accordingly. Grizzlies are performed in the following designs: gyratory, inertial, self-balancing and resonance. Motors powers for the grizzlies are from 7 to $20[\mathrm{~kW}$, which correspond to the line of average powers, oscillation amplitude is 3 $[\mathrm{mm}]$; the largest size of the finished product is from 100 to $150[\mathrm{~mm}]$, the tilt angle of the sieve is up to $25^{0}$ [7].

Electromagnetic shaker machine of the self-balancing grizzley (Figure 1) transmits up to 3000 oscillations per minute and amplitude of $0.3[\mathrm{~mm}]$ to the sieving surfaces.

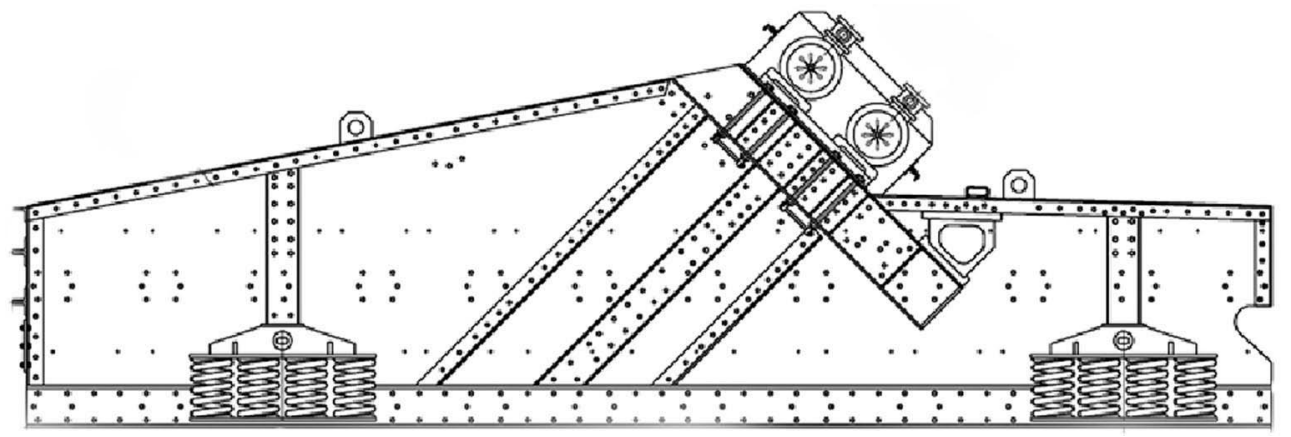

Fig. 1. Grizzley of self-balancing type

Therefore, the basic parameters of grizzley are

- the dimensions of the sieving surfaces,

- frequency and amplitude of oscillations,

- the tilt angle of the grizzley,

- the rotation direction of the shaker machine,

- the sieve motion trajectory.

\section{Research method}

In this paper a formation method of polyharmonic operation modes of the electromagnetic electroactivator of grizzley is proposed on the basis of the double-fed (DFM) (Figure 2) at different conditions of its implementation; analysis of the load parameters influence on the dynamic indicators of the operating motor was conducted. Well known, DFM using as an operating motor in comparison asynchronous motor [8] and the synchronous $[9,10]$ is an optimal solution; it is most versatile and has high energy characteristics [11-13]. Formation algorithm of ACD polyharmonic operation mode has been developed; it allows changing the oscillation frequency, phase shift and oscillation amplitude. This method allows to withstand requirements to self-balancing grizzley at the stage of necessary vibrations formation [14-18].

Polyharmonic operation mode (Figure 2) is realized at feeding stator and rotor windings by sinusoidal voltage (currents) with different frequencies, these frequencies are as different on the axes, i.e. $f_{1} \neq f_{2} \neq f_{3} \neq f_{4}$.

The following statements are true: $\omega_{1}=\omega_{3}=\omega, \omega_{2}=\omega^{\prime}, \omega_{4}=\omega^{\prime \prime}$ and $\alpha=\beta=\gamma=\varphi=0$ at polyharmonic operation mode of DFM. 


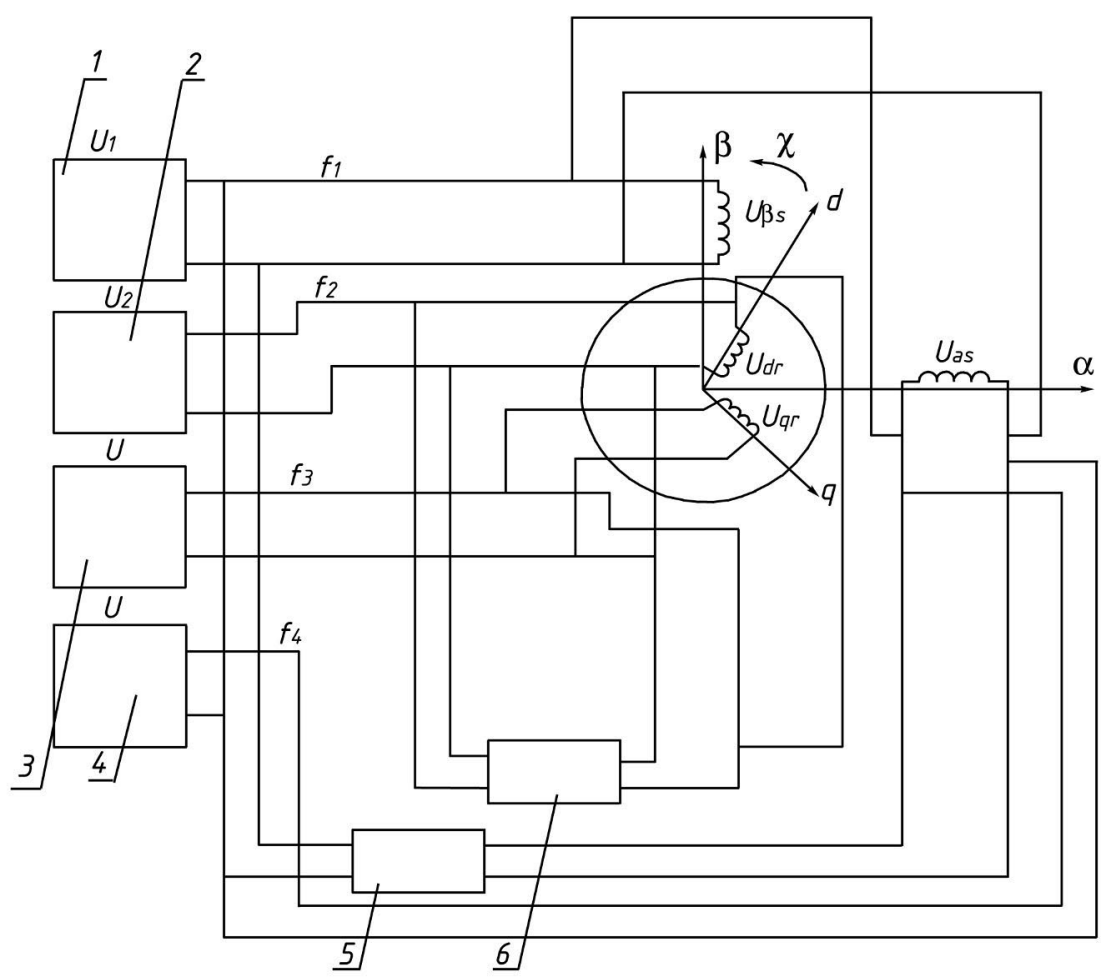

Fig. 2. Scheme of ACD inclusion with polyharmonic operation mode, where 1-4 are supply sources of the stator and rotor windings and 5, 6 are phase-shifting devices in the stator and rotor windings

Equations for the flux linkages of the stator and rotor windings in the transformed coordinate system are:

$$
\begin{gathered}
\psi_{\alpha s}=\psi_{m s} \sin (\omega t+\alpha) ; \\
\psi_{\beta r}=\psi_{m s} \sin \left(\omega^{\prime} t+\beta\right) ; \\
\psi_{\alpha r}=\psi_{m r} \sin (\omega t+\gamma) \cos \chi+\psi_{m r} \sin \left(\omega^{\prime} t+\varphi\right) \sin \chi ; \\
\psi_{\beta r}=-\psi_{m r} \sin (\omega t+\gamma) \sin \chi+\psi_{m r} \sin \left(\omega^{\prime} t+\varphi\right) \cos \chi,
\end{gathered}
$$

where $\psi_{m s}, \psi_{m r}$ are amplitude values of phase flux linkages of stator and rotor windings, $t$ is time, $\omega, \omega^{\prime}, \omega^{\prime \prime}$ are rotation angular frequencies of magnetic fields of stator and rotor along the axes $\alpha$ and $\beta$ and $\omega \neq \omega \neq \omega^{\prime \prime} ; \chi$ is motion law of the movable element of control motor.

Equations for squares of real and imaginary parts of generalized flux linkage are:

$$
\begin{gathered}
\psi_{\alpha}^{2}=\left(\psi_{m s} \sin (\omega t)+\left(\psi_{m r} \sin (\omega t) \cos \chi+\psi_{m r} \sin \left(\omega^{\prime \prime} t\right) \sin \chi\right)\right)^{2}= \\
=\left(\psi_{m s}\left(\sin (\omega t)+\mu\left(\sin (\omega t) \cos \chi+\sin \left(\omega^{\prime \prime} t\right) \sin \chi\right)\right)\right)^{2}, \\
\psi_{\beta}^{2}=\left(\psi_{m s} \sin (\omega t)-\left(\psi_{m r} \sin (\omega t) \sin \chi+\psi_{m r} \sin \left(\omega^{\prime} t\right) \cos \chi\right)\right)^{2}= \\
=\left(\psi_{m s}\left(\sin (\omega t)-\mu\left(\sin (\omega t) \sin \chi+\sin \left(\omega^{\prime \prime} t\right) \cos \chi\right)\right)\right)^{2},
\end{gathered}
$$

where $\mu=\psi_{\alpha r} / \psi_{\alpha s}$ is ratio between flux linkages of the stator and rotor along axis $\alpha$. 
Equation for the module of the resultant vector of flux linkage at polyharmonic operation mode is:

$$
\begin{aligned}
& \psi=\sqrt{\left(\psi_{m s}\left(\sin (\omega t)+\mu\left(\sin (\omega t) \cos \chi+\sin \left(\omega^{2} t\right) \sin \chi\right)\right)\right)^{2}+} \\
& \left.\overline{+(\psi m s}\left(\sin \left(\omega^{\prime} t\right)-\mu\left(\sin (\omega t) \sin \chi+\sin \left(\omega^{\prime \prime} t\right) \cos \chi\right)\right)\right)^{2}= \\
& =\psi_{m s} \sqrt{\left(\sin (\omega t)+\mu\left(\sin (\omega t) \cos \chi+\sin \left(\omega^{\prime \prime} t\right) \sin \chi\right)\right)^{2}+} \\
& \overline{+\left(\sin \left(\omega^{\prime} t\right)-\mu\left(\sin (\omega t) \sin \chi+\sin \left(\omega^{\prime} t\right) \cos \chi\right)\right)^{2}} \text {. }
\end{aligned}
$$

Equation for the motion law of dimensioned vector of flux linkage in the air gap at polyharmonic operation mode is:

$$
\begin{gathered}
\chi_{0}=\operatorname{arctg}\left(\frac{\psi_{m s} \sin \left(\omega^{`} t\right)-\psi_{m r} \sin (\omega t) \sin \chi+\psi_{m r} \sin \left(\omega^{\prime} t\right) \cos \chi}{\psi_{m s} \sin (\omega t)+\psi_{m r} \sin (\omega t) \cos \chi+\psi_{m r} \sin \left(\omega^{\prime} t\right) \sin \chi}\right)= \\
=\operatorname{arctg}\left(\frac{\sin \left(\omega^{`} t\right)-\mu\left(\sin (\omega t) \sin \chi+\sin \left(\omega^{\prime} t\right) \cos \chi\right)}{\sin (\omega t)+\mu\left(\sin (\omega t) \cos \chi+\sin \left(\omega^{\prime} t\right) \sin \chi\right)}\right) .
\end{gathered}
$$

Hodographs of resultant vector of flux linkage are below (Figure 3 ) at supplying stator and rotor windings from the power source and the voltage source.
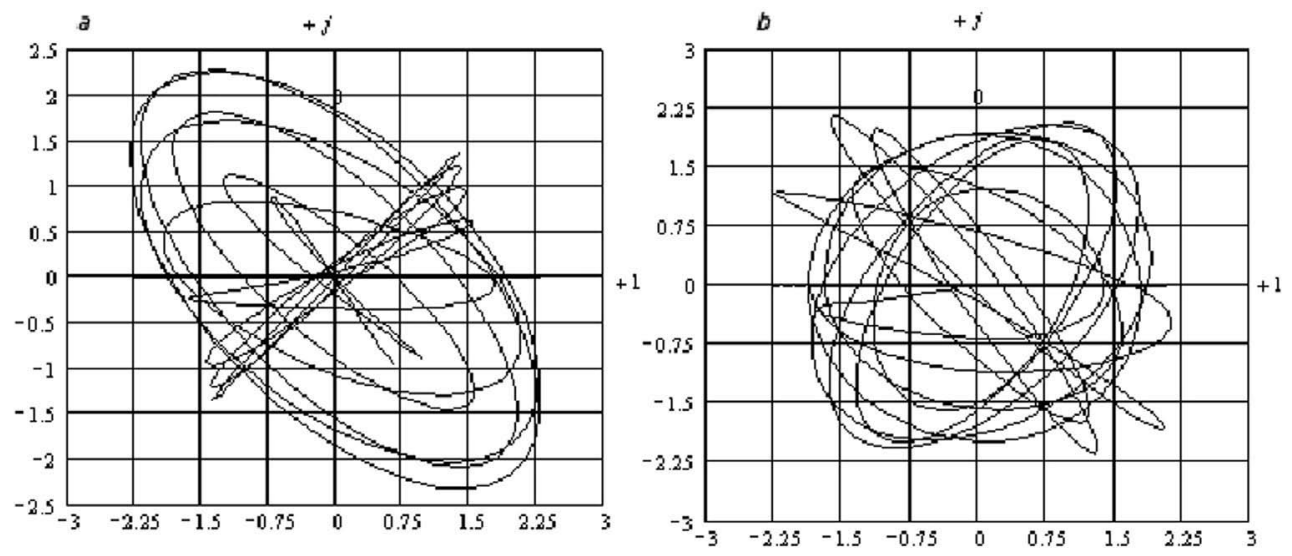

Fig. 3. Vectors hodographs $\psi_{0}$ at the feeding of the stator and rotor windings, where a - from the power source and $\mathrm{b}-$ from voltage source at the conditions $\omega_{1}=1.06, \omega_{2}=1, \omega_{3}=1.16, \omega_{4}=1.1$

\section{Results and discussion}

Equations for voltages on clamps of stator and rotor windings at realization of polyharmonic operation modes and concordant interaction of the electromagnetic fields of DFM in the transformed axes $\alpha, \beta, 0$ are:

$$
\begin{gathered}
U_{\alpha \mathrm{s}}=v_{1} U_{\mathrm{ms}} \sin \left(\omega_{1} \mathrm{t}+\alpha\right) ; \\
U_{\beta \mathrm{s}}=v_{2} U_{\mathrm{ms}} \sin \left(\omega_{2} \mathrm{t}+\beta\right) ; \\
U_{\alpha \mathrm{r}}=v_{3} U_{\mathrm{mr}} \sin \left(\omega_{3} \mathrm{t}+\gamma\right) \cos \chi+v_{3} U_{\mathrm{mr}} \sin \left(\omega_{4} \mathrm{t}+\varphi\right) \sin \chi \\
U_{\beta \mathrm{r}}=-v_{4} U_{\mathrm{mr}} \sin \left(\omega_{3} \mathrm{t}+\gamma\right) \sin \chi+v_{4} U_{\mathrm{mr}} \sin \left(\omega_{4} \mathrm{t}+\varphi\right) \cos \chi
\end{gathered}
$$

where $U_{\mathrm{ms}}, U_{\mathrm{mr}}$ are amplitude values of the phase voltages of stator and rotor windings; $v_{1}-$ $v_{4}$ are control signal coefficients; $\omega_{1}-\omega_{4}$ are angular frequencies of rotation of stator and 
rotor magnetic fields by axes $\alpha$ and $\beta ; \alpha, \beta, \gamma$ and $\varphi$ are initial phase shifts of supply voltages (currents) of stator and rotor windings of operating motor.

The Kron's equations are the basis of the mathematical model of DFM [4]. They describe the energy conversion in an electric machine and are represented by a system of differential equations, consisting of equations of voltages, and the equations of motion of the movable element of motor at general assumptions for ACD, working in special operation modes $[4,5,14-18]$. DFM was implemented on the example of electric machine type 4AK160S8U3 with synchronous rotation frequency $n_{0}=750[\mathrm{rpm}]$, power $P_{2}=5.5[\mathrm{~kW}]$, nominal stator current $I_{n}=18.35$ [A], $\eta=80$ [\%], $\cos \varphi_{n}=0.76$ [4].

Algorithms of formation of the vibrational and vibrational-rotational mode of operation to operating motor of ACD, working in " not normal" mode, are presented in Table 1. Also Table 1 shows the ways of polyharmonic operation modes getting (1, 3 and 4 ways) of operating motor for grizzley electroactivator.

Table 1. Algorithm of special modes formation on the basis of polyharmonic

\begin{tabular}{|c|c|c|c|c|c|}
\hline $\begin{array}{c}\text { Operation } \\
\text { mode of } \\
\text { operating } \\
\text { motor (DFM) }\end{array}$ & \begin{tabular}{|c|}
$\begin{array}{c}\text { Control } \\
\text { signal } \\
\text { coefficients } v_{i}, \\
{[p u]}\end{array}$ \\
\end{tabular} & $\begin{array}{c}\text { Angular frequency } \\
\text { of rotation of } \\
\text { windings magnetic } \\
\text { fields } \omega_{\mathrm{i}}[\mathrm{rad} / \mathrm{s}]\end{array}$ & $\begin{array}{c}\text { Phase shift } \\
\varphi,[\mathrm{rad}]\end{array}$ & $\begin{array}{c}\text { Magnetic fields } \\
\text { interaction }\end{array}$ & Application \\
\hline \multirow{2}{*}{ Vibrational } & $\begin{array}{c}v_{1}=v_{2}=1 ; \\
v_{3}=v_{4}=1.225\end{array}$ & $\omega_{1}=\omega_{2}=\omega, \omega_{3}=\omega_{4}=\omega^{`}$ & $\alpha=\beta=\gamma=\varphi=0$ & Concordant & $\begin{array}{c}\text { Ore } \\
\text { processing } \\
\text { form, soil } \\
\text { vibrating }\end{array}$ \\
\hline & $\begin{array}{c}v_{1}=v_{2}=1 ; \\
v_{3}=1.225 ; \\
v_{4}=-1.225\end{array}$ & $\omega_{1}=\omega_{2}=\omega, \omega_{3}=\omega_{4}=\omega^{\prime}$ & $\alpha=\beta=\gamma=\varphi=0$ & Opposing & \\
\hline $\begin{array}{l}\text { Vibrational- } \\
\text { rotational }\end{array}$ & $\begin{array}{c}v_{1}=v_{2}=1 ; \\
v_{3}=v_{4}=1.225\end{array}$ & $\begin{array}{c}\omega_{1}=\omega_{2}=\omega_{3}=\omega, \\
\omega_{4}=\omega^{`}\end{array}$ & $\begin{array}{c}\alpha=\beta=\gamma=0, \\
\varphi=\pi / 2\end{array}$ & Concordant & \begin{tabular}{|c|} 
Vibrotrans- \\
portation \\
and coal \\
vibro-sorting \\
\end{tabular} \\
\hline \multirow{4}{*}{ Polyharmonic } & $\begin{array}{c}v_{1}=v_{2}=1 ; \\
v_{3}=v_{4}=1.225 \\
\text { (1 way) }\end{array}$ & $\begin{array}{c}\omega_{1}=\omega_{3}=\omega \\
\omega_{2}=\omega^{\prime} \\
\omega_{4}=\omega^{\prime \prime}\end{array}$ & $\alpha=\beta=\gamma=\varphi=0$ & Concordant & \multirow{4}{*}{$\begin{array}{l}\text { Primary coal } \\
\text { fragmenting }\end{array}$} \\
\hline & $\begin{array}{c}v_{1}=v_{2}=1 ; \\
v_{3}=v_{4}=1.225 \\
\text { (2 way) }\end{array}$ & $\begin{array}{c}\omega_{1}=\omega_{2}=\omega \\
\omega_{3}=\omega^{\prime} \\
\omega_{4}=\omega^{\prime \prime}\end{array}$ & $\alpha=\beta=\gamma=\varphi=0$ & Concordant & \\
\hline & $\begin{array}{c}v_{1}=v_{2}=1 ; \\
v_{3}=v_{4}=1.225 \\
\text { (3 way) }\end{array}$ & $\begin{array}{c}\omega_{1}-\omega_{2}=\omega_{3}-\omega_{4} \\
\text { (frequency is not } \\
\text { multiple of } 5 \mathrm{~Hz} \text { ) }\end{array}$ & $\alpha=\beta=\gamma=\varphi=0$ & Concordant & \\
\hline & $\begin{array}{c}v_{1}=v_{2}=1 ; \\
v_{3}=v_{4}=1.225 \\
\text { (4 way) }\end{array}$ & $\begin{array}{c}\omega_{2}-\omega_{1}=\omega_{4}-\omega_{3} \\
\text { (frequency is } \\
\text { multiple of } 5 \mathrm{~Hz} \text { ) }\end{array}$ & $\alpha=\beta=\gamma=\varphi=0$ & Concordant & \\
\hline
\end{tabular}

Figures 4-6 show dependences of transition process time $\tau_{t p}$, amplitude values of angular speed of rotation $\omega_{s v}$, amplitude values of motion law $\chi_{m}$, on load inertia moment $J_{n}$ and coefficient of damping moment of load $R_{g}$, where dependence 1 is at $f_{1}=f_{3}=50[\mathrm{~Hz}]$, $f_{2}=52[\mathrm{~Hz}], f_{4}=55[\mathrm{~Hz}]$, dependence 2 is at $f_{1}=50[\mathrm{~Hz}], f_{2}=55[\mathrm{~Hz}], f_{3}=53[\mathrm{~Hz}], f_{4}=63[\mathrm{~Hz}]$ and dependence 3 is $f_{1}=53[\mathrm{~Hz}], f_{2}=50[\mathrm{~Hz}], f_{3}=58[\mathrm{~Hz}], f_{4}=55[\mathrm{~Hz}]$.

Transient process time at increasing load parameters behaves differently: it increases at increasing load inertia moment $J_{n}$ and decreases at increasing coefficient of damping moment of load $R_{g}$. 

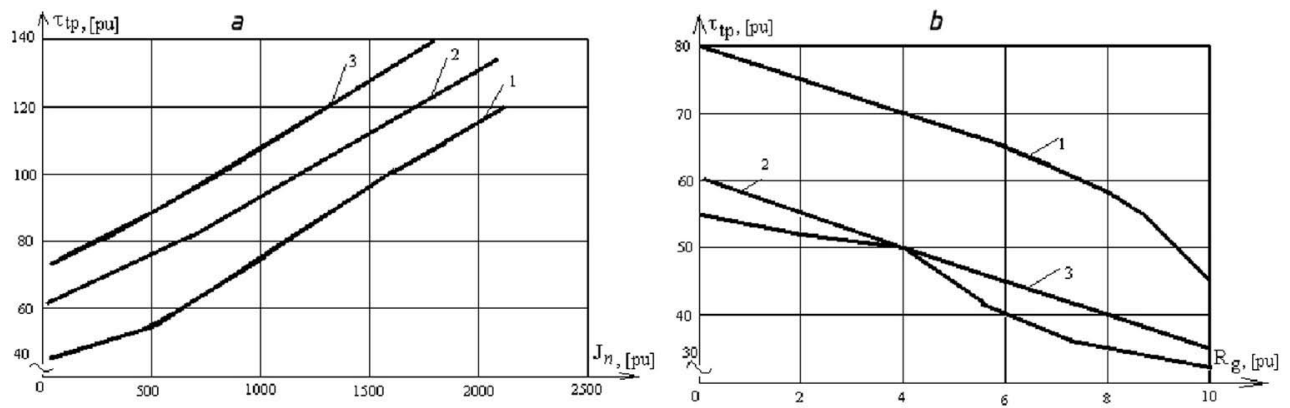

Fig. 4. Dependences of transition process time $\tau_{t p}$ on a - load inertia moment $J_{n}$ and b-coefficient of damping moment of load $R_{g}$

Steady-state values of angular speed $\omega_{\mathrm{Sv}}$ are decreased at increasing load parameters, but their character is different: characteristics have a pronounced exponential character at increasing load inertia moment $J_{n}$ in any method of polyharmonic mode forming. Researched dynamic parameters have more linear character with increasing coefficient of damping moment of load $R_{g}$, at that, 4 way of mode formation has the highest nonlinearity (Table 1).
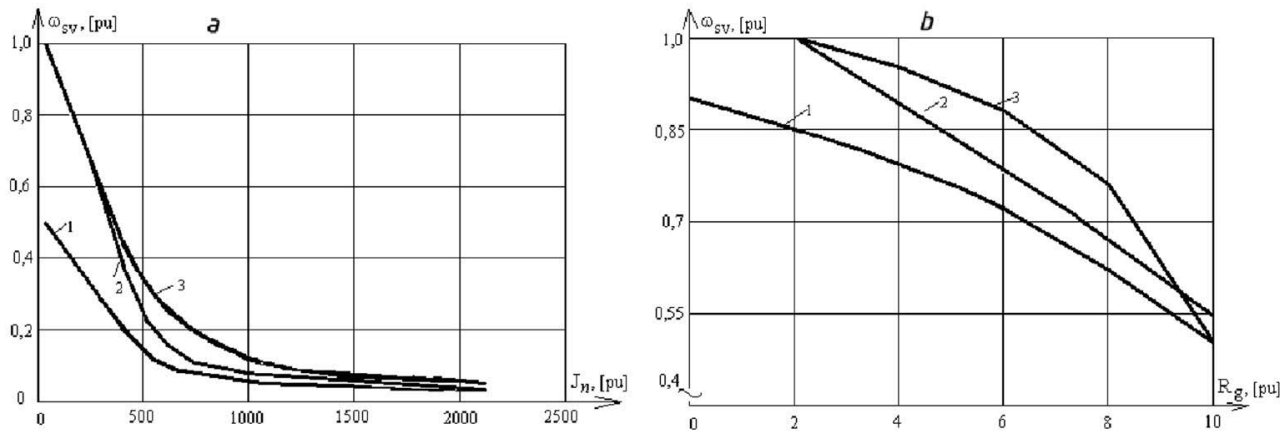

Fig. 5. Dependences of steady-state values of angular speed of rotation $\omega_{\mathrm{sv}}$ on: a) load inertia moment $J_{n}$ and b) coefficient of damping moment of load $R_{\mathrm{g}}$
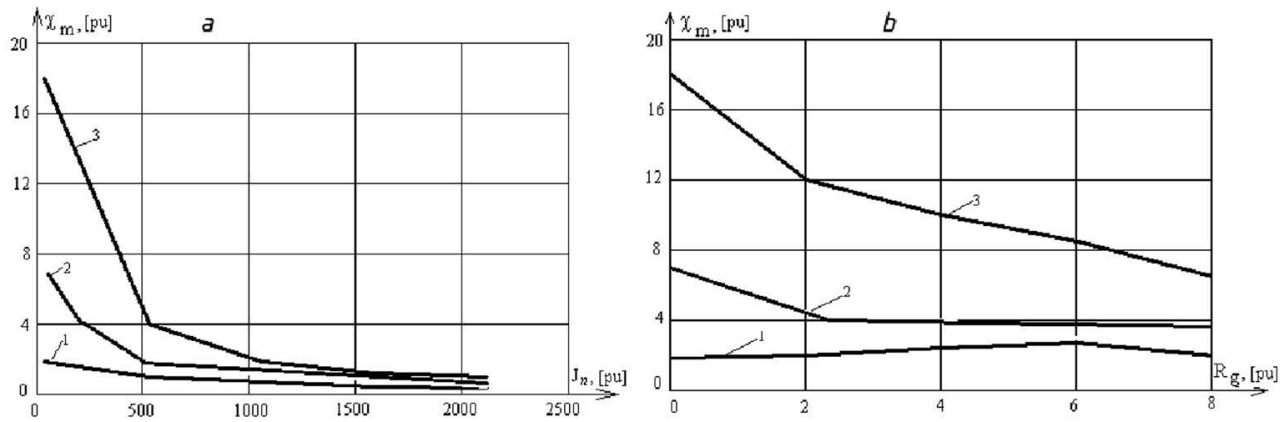

Fig. 6. Dependences of amplitude values of motion law $\chi_{\mathrm{m}}$ on a - load inertia moment $J_{n}$ and b coefficient of damping moment of load $R_{\mathrm{g}}$.

Character of amplitude values changes of the motion law of motor shaft $\chi_{m}$ in dependence on the load parameters has exponential nature. Moreover, the load inertia moment $J_{n}$ has the greatest impact, because $\chi_{m}$ is reduced by 3.5 times; dependence 1 has a resonance peak at the point $R_{g}=6.0[\mathrm{pu}]$ at increasing of coefficient of damping moment of load (Figure 6b). 


\section{Conclusions}

1. Increase of load inertia moment $J_{n}$ leads to increasing transition process time $\tau_{t p}$ and to decreasing other dynamic indicators with pronounced exponential character.

2.Increase of coefficient of damping moment of load leads to decreasing dynamic indicators of the operating motor: amplitude values for motion law have exponential nature, the rest of the parameters have linear.

3. Proposed algorithms of formation of the special operation modes of the operating motor simply to implement, so they have all prerequisites for use in equipment for mining industry.

\section{References}

1. D. Bevz, L. Payuk, N. Voronina, MATEC Web of Conferences 91, 01037 (2017)

2. A.V. Glazachev, Yu.N. Dementyev, K.N. Negodin, A.D. Umursakova, EPJ Web of Conferences 110, 01044 (2016)

3. A. Schwery, T. Kunz, BWK-Energie-Fachmagazin 64(7-8), 21 (2014)

4. L. Payuk, N. Voronina, S. Korepanov, O. Galtseva, N. Natalinova, MATEC Web of Conferences 79, 01060 (2016)

5. A.V. Aristov, V.O. Nagorniy, A.M. Gavrilov, Proc. of SIBCON 15287708 (2015)

6. N.M. Natalinova, O.V. Galtseva, E.A. Moldovanova, Proc. of EECEA 7470765, 52 (2016)

7. A.V. Aristov, L.I. Aristova, I.A. Ekkert, Proc. of MEACS 15805203 (2015)

8. E.A. Kolomiyet, A.Y. Chernyshyov, Proc. of SIBCON 15287590 (2015)

9. V.G. Bukreev, S.V. Lyapushkin, M.M. Edgulov, MATEC Web of Conferences 37, 01012 (2015)

10. I.G. Odnokopylov, V.V. Gneushev, I.A. Larioshina, J. Phys.: Conf. Ser. 671, 012044 (2016)

11. L.A. Payuk, N.A. Voronina, O.V. Galtseva, J. Phys.: Conf. Ser. 671, 012044 (2016)

12. S Williamson, A.C. Ferreira, A.K. Wallace, IEE Proceedings: Electric Power Applications 144(2), 5604026 (2002)

13. S Williamson, A.C. Ferreira, IEE Proceedings: Electric Power Applications 144(2), 5604027 (2002)

14. T. Lugand, A. Schwery, Proc. of ICEM 7732826, 2191 (2016)

15. L.A. Vaisberg, T.M. Baldaeva, K.S. Ivanov, A.A. Otroshchenko, Mineral processing 1 (2016)

16. G. Wang, X. Tong, Mining Science and Technology (China) 21(3), 451 (2011)

17. T. Dyr, P. Wodzinski, Physicochem. Problems of Mineral Processing 35, 147 (2002)

18. H. Dong, C. Liu, Y. Zhao, Int. J. of Mining Science and Technology 23(1), 95 (2013) 